\title{
Time Perspectives as The Predictors of Online Self-Regulated Learning
}

\author{
Andrea Barta ${ }^{1,2(\bowtie)}$, Borbála Tamás ${ }^{1,2}$, Bernadette Gálfi $^{1,2}$ and István Szamosközi ${ }^{2}$ \\ ${ }^{1}$ Department of Applied Psychology, Faculty of Psychology and Educational Sciences, Babeș-Bolyai \\ University, Cluj-Napoca, Romania \\ 2 Evidence-Based Psychological Assessment and Interventions Doctoral School, Babeș-Bolyai \\ University, Cluj-Napoca, Romania \\ andrea.barta@ubbcluj.ro
}

\section{ABSTRACT}

Digital education considerably requires active participation of students in the learning process, the application of self-regulated learning activities for the attainment of successful learning results. The aim of the present study is the investigation of time perspectives as the predictors of online self-regulated learning. In our study 210 Transylvanian students participated, from the Babeș-Bolyai University, Faculty of Psychology and Educational Sciences. Students' demographic characteristics were recorded, for the assessment of self-regulation the Self-regulated Online Learning Questionnaire - Revised was applied and time perspectives of students were measured by the Zimbardo Time Perspective Inventory. A correlational, cross-sectional design was used. On the basis of the results of hierarchical regression, in our first model demographic characteristics explained $5 \%$ of the variance for the application of selfregulation activities. In our second model, controlling demographic variables, time perspectives explained an additional $33 \%$ of the variance for self-regulation. Self-regulated learning strategies are predicted among demographic characteristics by students' gender, age and online learning, while out of time perspectives only future orientation proved to be a significant predictor. Females, older students, participants attending online education and higher future orientation apply to a higher degree the selfregulated learning strategies as males, younger students and participants with lower scores at future orientation.

Keywords: self-regulated strategies, metacognitive activities, time perspectives, future orientation, hierarchical regression

Cite this article as: Barta, A., Tamás, B., Gálfi, B., \& Szamosközi, I. (2021). Time Perspectives as The Predictors of Online Self-Regulated Learning. Journal of e-learning Research, 1(2), 32-40. https://doi.org/10.33422/jelr.v1i2.73

\section{Introduction}

Self-regulated learning is an indispensable precondition of the succesful academic achievement (Davis \& Hadwin, 2021; Li et al., 2020). Students participation as active learners in the online, digital education process has a considerable importance, since students have the responsibility to shape a structured learning environment, which is provided by the educational institution during face-to-face education (Cerezo et al., 2020; Hong et al., 2021; Yu et al., 2020).

Online self-regulated learning includes metacognitive activities, which mainly enable the monitoring of comprehension and its contribution to high academic achievement (Lee, et al.,

(C) The Author(s). 2022 Open Access. This article is distributed under the terms of the Creative Commons Attribution 4.0 International License, which permits unrestricted use, distribution, and redistribution in any medium, provided that the original author(s) and source are credited. 
2020; Wong et al., 2021). Students apply different metacognitive strategies before, during and after learning (Carter et al., 2020). Metacognitive activities before learning include the planning of the learning process, goal setting, monitoring and selection of earlier knowledge, which might help with understanding of the new information during courses and doing homework. These activities also refer to the systematizing and selection of learning strategies, which are applicable in case of different subjects. Metacognitive activities during learning indicate the application of adequate learning strategies, precise time management, mapping the relationships between information acquired on different subjects, comprehension monitoring. After learning, students monitor their recalling performance, namely through their meta-memory, as they try to find out which parts of the acquired knowledge require further learning. They also examine in what degree were successful in their previously established goals, evaluate their results, monitor which of the applied strategies were unsuccessful, demanding substitution (Lee, et al., 2020; Wong et al., 2021).

During time management, which is another part of self-regulated learning, students regulate their time allocated for learning, establish the duration and concentrate on the learning process and on no other activities during the study time (Lee, et al., 2020; Walters \& Brady, 2020). During online learning the places for studying are not provided by the faculty (classrooms, library), students need to create the ideal learning environment for themselves by appointing a place where their only focus is learning, avoiding disturbing factors (Lee, et al., 2020). During online learning students need to have a higher motivation for maintaining attention, to choose learning over resting opportunities, even when they find the curriculum boring, outside of their interest area or if the subject seems too complicated. Another selfregulated learning activity is help seeking, the cooperation between the students and teachers can be advantages in resolving complex assignments (Cerezo et al., 2020; Zhu et al., 2020).

Time perspective is a cognitive construct that involves past, present, and future experience of the psychological concepts of time, that an individual experience over certain personal and social interactions. These experiences of time result in giving order, coherence and meaning to those events (Orkibi \& Ronen, 2019). Zimbardo and Boyd (1999) defined 5 temporal dimensions: past positive (recalling past events nostalgically positive), past negative (accounting for past events as distressful), present hedonistic (considering the present as overly important, seeking for immediate pleasure and gratification), present fatalistic (sensing future events as catastrophic, lacking control over those events), and future (having a goaloriented mentality, a tendency to delay immediate rewards).

Previous study results indicate that present time perspective is associated with substance abuse, however future oriented time perspective reduces the risk of addictive behaviors (Kim et al., 2017), and it is associated also with better financial management (Hodgins \& Engel, 2002) and better self-control (Mucha et al., 2020), whereas individuals with high score in past negative, present fatalistic or present hedonistic time perspectives tend to have trouble controlling aggression at the affective and also at the physical levels (Stolarski et al. 2016).

The application of self-regulated learning strategies could be predicted by students' dominant time perspective. Earlier studies highlighted a positive association between future orientation and self-regulated learning (de Bilde et al., 2011; Pérez et al., 2017; Yuzarion et al., 2020). Future orientation is the predictor of academic achievement, and their relationship is amplified by the use self-regulated learning activities (Pérez et al., 2017). Students focusing 
on past and present apply less metacognitive strategies in planning of their future steps, than future oriented students, who are more interested and motivated in reaching their goals which result in academic success, so they plan their activities for studying, carefully manage their time and create the most ideal environment for learning (de Bilde et al., 2011; Yuzarion et al., 2020).

\subsection{Objectives}

The aim of the present study is the establishment of the explaining power of time perspectives in the prediction of online self-regulated learning activities, after controlling demographic variables (gender, age, online education). We would like to investigate which time perspectives predict significantly the application of self-regulated learning strategies among Transylvanian students.

\section{Materials and Methods}

\subsection{Participants}

In the present study 214 undergraduate students, from the Babeș-Bolyai University, Faculty of Psychology and Educational Sciences participated. After the identification of the outliers, the sample size decreased to 210 participants. The mean age of students was 22 years old, 181 women and 29 men participated. The majority of students didn't participate in online education before the COVID-19 pandemic, but during the data recording (April 2020) 97.1\% of participants received online education (Table 1).

Table 1.

Demographic characteristics of participants

\begin{tabular}{lcc}
\hline \multicolumn{1}{c}{ Demographic characteristic } & n & \% \\
\hline Gender & 181 & 86.2 \\
Female & 29 & 13.8 \\
Male & & \\
Earlier online education & 28 & 13.3 \\
Yes & 182 & 86.7 \\
No & & \\
Online education in present & 204 & 97.1 \\
Yes & 6 & 2.9 \\
No &
\end{tabular}

\subsection{Instruments}

In the demographic questionnaire relevant characteristics of students (gender, age, participation in online education) were recorded.

For the assessment of self-regulated learning the Self-Regulated Online Learning Questionnaire - Revised (Jansen et al., 2018) was used, which contains 42 statements, 7 subscales: metacognitive activities before learning ( 7 items, $\alpha=0.827$ ), metacognitive activities during learning ( 7 items, $\alpha=0.784$ ), metacognitive activities after learning ( 6 items, $\alpha=0.797$ ), time management ( 5 items, $\alpha=0.715$ ), environmental structuring ( 4 items, $\alpha=$ 0.718 ), persistence ( 7 items, $\alpha=0.834$ ), help seeking (6 items, $\alpha=0.832$ ). Participants 
formed a judgement on a 7 point Likert scale regarding how representative are the statements were for them ( $1=$ 'not at all true for me'; $7=$ 'very true for me'). The overall questionnaire has a high reliability on the investigated sample (42 items, $\alpha=0.938$ ).

For the measurement of students' time perspectives the Zimbardo Time Perspective Inventory (Zimbardo \& Boyd, 1999) was used. The instrument contains 56 statements, participants estimated on 5 point Likert scale in what degree the given statement is characteristic of them ( 1 = 'very uncharacteristic', $2=$ 'uncharacteristic', $3=$ 'neutral', $4=$ 'characteristic', $5=$ 'very characteristic'). The inventory measures 5 different time perspectives: past negative (11 items, $\alpha=0.844)$, past positive ( 8 items, $\alpha=0.806$ ), past negative (11 items, $\alpha=0.844$ ), present-hedonistic (15 items, $\alpha=0.805$ ), present-fatalistic ( 9 items, $\alpha=0.715$ ), and future time perspective (13 items, $\alpha=0.740$ ).

\subsection{Design and procedure}

We applied cross-sectional, correlational design, measuring the predictive power of time perspectives for self-regulated learning, controlling the demographic variables.

Students gave their informed consent for the participation in the study. Convenience sampling was applied and the data recording was performed in an online form. The questionnaires took approximately 15 minutes to fill. The demographic questionnaire was filled in first, then the questionnaires measuring self-regulated learning and time perspectives.

\subsection{Data analysis}

A priori power analysis via G*Power3 (Faul et al., 2007) for hierarchical linear regression based on type I error with a p-value of 0.05 and statistical power of 0.80 with five tested predictors (total number of predictors 9 ) showed that for a medium effect size $\left(f^{2}=0.15\right)$ the required sample size is $n=92$. Thus, the sample size $(n=210)$ is suitable for detecting medium effect sizes.

\section{Results}

Based on Skewness and Kurtosis indicators, visual inspection, and Q-Q plot of the data, the sample has a mostly normal distribution (Table 2).

Table 2.

Descriptive statistics and normality

\begin{tabular}{lcccccc}
\hline \multicolumn{1}{c}{ Variable } & $\boldsymbol{M}$ & $\boldsymbol{S D}$ & Min. & Max. & Skewness & Kurtosis \\
\hline Self-regulated learning & 161.77 & 32.61 & 82 & 241 & -0.121 & -0.556 \\
Past-negative TP & 33.71 & 8.70 & 13 & 55 & -0.046 & -0.564 \\
Past-positive TP & 30.38 & 5.68 & 12 & 40 & -0.627 & 0.185 \\
Present-hedonistic TP & 50.58 & 8.66 & 28 & 72 & -0.316 & -0.391 \\
Present-fatalistic TP & 21.93 & 5.48 & 9 & 36 & 0.049 & -0.313 \\
Future TP & 46.23 & 7.10 & 28 & 65 & 0.052 & -0.433 \\
\hline
\end{tabular}

Notes. $\mathrm{TP}=$ time perspective; Min. $=$ minimum; Max. $=$ maximum

Students' mean scores and standard deviations of self-regulated learning and time perspectives are presented in Table 2. 
The results of the hierarchical regression demonstrated that the demographic variables (gender, age, earlier online learning and online learning in present) accounted for a significant $5 \%$ of variance in self-regulated learning, adjusted $R^{2}=0.05, F(4,205)=4.270, p$ $=0.002$. Within demographic variables (Table 3, Model 1) students' gender $(\beta=0.14, p=$ $0.042)$, age $(\beta=0.14, p=0.033)$, and online learning in present $(\beta=0.18, p=0.007)$ made a unique statistically significant contribution to the model predicting self-regulated learning.

Table 3.

Hierarchical regression results for self-regulated learning

\begin{tabular}{|c|c|c|c|c|c|c|}
\hline \multirow{2}{*}{ Variable } & \multicolumn{3}{|c|}{ Model 1} & \multicolumn{3}{|c|}{ Model 2} \\
\hline & $\boldsymbol{B}$ & $\boldsymbol{\beta}$ & $S E$ & $\boldsymbol{B}$ & $\boldsymbol{\beta}$ & $S E$ \\
\hline Constant & 100.05 & & 15.58 & 16.84 & & 24.76 \\
\hline Gender & $13.33 *$ & 0.14 & 6.50 & 5.63 & 0.06 & 5.36 \\
\hline Age & $0.68 *$ & 0.14 & 0.32 & 0.29 & 0.06 & 0.28 \\
\hline Earlier online education & 1.29 & 0.01 & 6.74 & 2.20 & 0.02 & 5.52 \\
\hline Online education in present & $35.94 * *$ & 0.18 & 13.17 & $22.91 *$ & 0.11 & 10.84 \\
\hline Past-negative TP & & & & -0.28 & -0.07 & 0.25 \\
\hline Past-positive TP & & & & 0.61 & 0.10 & 0.39 \\
\hline Present-hedonistic TP & & & & 0.21 & 0.05 & 0.23 \\
\hline Present-fatalistic TP & & & & -0.76 & -0.12 & 0.39 \\
\hline Future TP & & & & $2.33 * * *$ & 0.50 & 0.30 \\
\hline$R^{2}$ & \multicolumn{3}{|c|}{0.07} & \multicolumn{3}{|c|}{0.41} \\
\hline Adj. $R^{2}$ & \multicolumn{3}{|c|}{$0.05 * *$} & \multicolumn{3}{|c|}{$0.38 * * *$} \\
\hline$\Delta R^{2}$ & & & & \multicolumn{3}{|c|}{$0.33 * * *$} \\
\hline
\end{tabular}

In Step 2, time perspectives explained an additional $33 \%$ of the variance, $\Delta R^{2}=0.334, F_{\text {change }}$ $(5,200)=22.709, p<0.001$. The adjusted $R^{2}$ values (Table 3$)$ show increases in the variance explained by the two model, with the second model explaining $38 \%$ of the variance for selfregulated learning, $F(9,200)=15.518, p<0.001$.

From demographic variables only online learning in present $(\beta=0.11, p=0.036)$, and within time perspectives only future time perspective $(\beta=0.50, p<0.001)$ made a unique statistically significant contribution to the final model predicting self-regulated learning.

\section{Discussion}

On basis of our results students' demographic characteristics, gender, age and online education are significant predictors of self-regulated learning. Regarding to gender, females apply more self-regulated learning activities than males. This result corresponds with earlier research findings (Pérez et al., 2017; Susilowati et al., 2020), which also found that women use metacognitive strategies more often, plan the study process and manage their time more effective than men. In the study of Elfakki et al. (2021) also was established that females achieved higher scores on four domains of self-regulation: help-seeking, environmental structuring, time management and self-evaluation. Li (2019) also concluded that women apply self-regulated strategies regarding to the environmental structuring more often.

We also detected that older students apply self-regulated strategies with a higher success, than younger participants, namely age predicts in a positive direction the degree of self- 
regulation. Price and Murray (2012), as well as Miles and Stine-Morrow (2004) established that older adults metacognitive strategies, such as the evaluation, monitoring of the solving of assignments are more developed than younger adults. This result can be explained with the amount of experiences in learning activities of older participants, having more knowledge about different learning strategies and their own cognitive abilities, compared with younger students.

Online education is also a significant predictor of self-regulated learning. The use of selfregulated strategies is an essential requirement for successful accomplishments in digital education. Learning in an online sphere requires from students to plan ahead in terms of both the strategies used and the creation of appropriate learning environment. Students require a higher level of self-control in the elimination of disturbing factors and other activities, than in the case of face-to-face education (Cerezo et al., 2020; Hong et al., 2021; Yu et al., 2020).

By controlling the demographic variables, it was investigated which time-perspectives predict self-regulated learning strategies more significantly. All in all the 5 time perspectives accounted for the variance of self-regulated learning, however only future time perspective has a significant unique contribution to the final model, explaining the application of selfregulated activities, which result corresponds with the earlier research findings (de Bilde et al., 2011; Pérez et al., 2017; Yuzarion et al., 2020). Future oriented students put emphasis on the achievement of high academic results, which determines the accomplishment of their further study and career goals. In this manner they plan in advance their learning activities, applying their metacognitive strategies, they are open to change their strategy to achieve their future goals, namely the high academic results, if the current applied strategy is not suitable. They evaluate their results and the possible sources of low achievements after learning, to avoid the same mistakes in the future. With the help of future orientation time management, environmental structuring also becomes more effective, and students are more motivated to seek help, to communicate with professors in the interest of high achievements. In contrast with future orientation past orientation could divert students' attention from the future goals and from the planning of learning. Present orientation could prevent students from excluding disturbing factors or alternative activities during the learning process.

\subsection{Limitations and future directions}

One of the main limitations of our study is the unequal gender distribution. In this research mostly females participated, thus the results are not generalizable reliably for male students. It is possible that we would find other results with more male participants, as earlier studies highlighted gender differences in self-regulated learning (Pérez et al., 2017; Susilowati et al., 2020).

An another limitation of the study is the application of self-reported questionnaires, which could result response bias. The usage of more objective instruments (tests) or the investigation of self-regulated learning strategies during the solving of an academic assignment, could exclude biases derived from filling self-reported questionnaires.

As a result of convenience sampling the non-response bias could appear, so students registered as volunteers in the study, might differ from non-participating students. The generalization spectrum of our conclusions could be broadened with the application of random sampling, instead of convenience sampling. In the interest of the generalization of 
our results for the whole Transylvanian student community, with the help of cluster sampling we could recruit participants in our study from every faculty major.

Next to demographic variables and time perspectives, numerous cognitive and motivational factors exist, which could explain the correct application of self-regulated strategies. In further studies it would be meritorious to investigate the predictive power of critical thinking, as a cognitive ability, as well as achievement motivation for self-regulated learning. Our further aim is to detect the relationship between self-regulated learning and academic achievement, respectively the moderating effect on the association of time perspectives, educational variables, such as major (science subjects, humanities, arts), participation and results in extracurricular activities.

Furthermore, it would be worth to conduct a longitudinal study, instead of cross-sectional design, to establish the long term consequences of online education for self-regulated learning, respectively to examine the possible prediction of further career success by selfregulated learning.

\section{Conclusions}

This study demonstrated the significant explaining power of time perspectives for the variation of self-regulated learning activities. Among time perspectives, future orientation is a significant predictor of self-regulated learning, but the unique prediction of the past positive, past negative, present fatalistic and present hedonistic time perspectives are statistically insignificant after controlling demographic variables. Students with higher future orientation apply more self-regulated learning strategies than students paying less attention to their future.

In view of demographic variables, self-regulated learning is more characteristic for females and older students, for online education, than for males, younger students and students participating in face-to-face education. However one of the main limitations of this study is the homogeneity of participants along demographic characteristics, so these conclusions are generalizable only for one part of Transylvanian undergraduate students (principally for online educated females from the Department of Psychology and Educational Sciences).

\section{References}

Carter, R. A., Rice, M., Yang, S., \& Jackson, H. A. (2020). Self-regulated learning in online learning environments: Strategies for remote learning. Information and Learning Sciences, 121(5/6), 321329. https://doi.org/10.1108/ILS-0 HYPERLINK "https://doi.org/10.1108/ILS-04-2020-0114"4$\underline{2020-0114}$

Cerezo, R., Bogarín, A., Esteban, M., \& Romero, C. (2020). Process mining for self-regulated learning assessment in e-learning. Journal of Computing in Higher Education, 32(1), 74-88. https://doi.org/10.1007/s12528-019-09225-y

Davis, S. K., \& Hadwin, A. F. (2021). Exploring differences in psychological well-being and selfregulated learning in university student success. Frontline Learning Research, 9(1), 30-43. https://doi.org/10.14786/flr.v9i1.581 
de Bilde, J., Vansteenkiste, M., \& Lens, W. (2011). Understanding the association between future time perspective and self-regulated learning through the lens of self-determination theory. Learning and Instruction, 21(3), 332-344. https://doi.org/10.1016/j.learninstruc.2010.03.002

Elfakki, F. A. M., Alamri, M. M., Ashraful, I., Elnimeiri, M., \& Frah, E. (2021). Self-Regulated Learning in the University of Tabuk: Gender Differences in Strategy and Outcomes. Rwanda Journal of Medicine and Health Sciences, 4(1), 151-165. https://doi.org/10.4314/rjmhs.v4i1.11

Faul, F., Erdfelder, E., Lang, A., \& Buchner, A. (2007). G*Power 3: a flexible statistical power analysis program for the social, behavioral, and biomedical sciences. Behavior Research Methods, 39, 175-191. https://doi.org/10.3758/BF03193146

Hodgins, D. C., \& Engel, A. (2002). Future time perspective in pathological gamblers. Journal of Nervous and Mental Disease, 190(11), 775-780. https://doi.org/10.1097/00005053-200211000$\underline{00008}$

Hong, J.-C., Lee, Y.-F., \& Ye, J.-H. (2021). Procrastination predicts online self-regulated learning and online learning ineffectiveness during the coronavirus lockdown. Personality and Individual Differences, 174, 110673. https://doi.org/10.1016/j.paid.2021.110673

Jansen, R. S., van Leeuwen, A., Janssen, J., \& Kester, L. (2018). Validation of the Revised Selfregulated Online Learning Questionnaire. In V. Pammer-Schindler, M. Pérez-Sanagustín, H. Drachsler, R. Elferink, \& M. Scheffel (Eds.), Lifelong Technology-Enhanced Learning (Vol. 11082, pp. 116-121). Springer International Publishing. https://doi.org/10.1007/978-3-319-98572$\underline{5} \underline{9}$

Lee, D., Watson, S. L., \& Watson, W. R. (2020). The Influence of Successful MOOC Learners' SelfRegulated Learning Strategies, Self-Efficacy, and Task Value on Their Perceived Effectiveness of a Massive Open Online Course. The International Review of Research in Open and Distributed Learning, 21(3). https://doi.org/10.19173/irrodl.v21i3.4642

Li, S., Chen, G., Xing, W., Zheng, J., \& Xie, C. (2020). Longitudinal clustering of students' selfregulated learning behaviors in engineering design. Computers \& Education, 153, 103899. https://doi.org/10.1016/j.compedu.2020.103899

Miles, J. R., \& Stine-Morrow, E. A. L. (2004). Adult Age Differences in Self-Regulated Learning From Reading Sentences. Psychology and Aging, 19(4), 626-636. https://doi.org/10.1037/0882$\underline{7974.19 .4 .626}$

Mucha, M., Wiśniewska, M., \& Nęcka, E. (2020). Time perspective and self-control: metacognitive management of time is important for efficient self-regulation of behavior. Current Issues in Personality Psychology, 8(2), 83-91. https://doi.org/10.5114/cipp.2020.97286

Orkibi, H., \& Ronen, T. (2019). A dual-pathway model linking self-control skills to aggression in adolescents: Happiness and time perspective as mediators. Journal of Happiness Studies: An Interdisciplinary Forum on Subjective Well-Being, 20(3), 729-742. https://doi.org/10.1007/ $\underline{\text { s10902-018-9967-1 }}$

Pérez, S. H., Braojos, G. C., \& Fernández, R. S. (2017). The relationship of gender, time orientation, and achieving self-regulated learning. Revista de Investigación Educativa, 35(2), 353. https://doi.org/10.6018/rie.35.2.273141

Price, J., \& Murray, R. G. (2012). The Region of Proximal Learning Heuristic and Adult Age Differences in Self-Regulated Learning. Psychology and Aging, 27(4), a0029860.supp., 11201129. https://doi.org/10.1037/a0029860.supp 
Stolarski, M., Zajenkowski, M., \& Zajenkowska, A. (2016). Aggressive? From time to time... uncovering the complex associations between time perspectives and aggression. Current Psychology, 35(4), 506-515. https://doi.org/10.1007/s12144-016-9422-6

Susilowati, N., Lestari, S., Yuniarsih, D., \& Maharani, D. H. (2020). Investigating Self-Regulated Learning Differences Based on Gender, Scholarship, and Student's Housing. Jurnal Pendidikan Ekonomi Dan Bisnis (JPEB), 8(1), 25-33. https://doi.org/10.21009/JPEB.008.1.3

Wolters, C. A., \& Brady, A. C. (2020). College Students' Time Management: A Self-Regulated Learning Perspective. Educational Psychology Review. https://doi.org/10.1007/s10648-020-09519-z

Wong, J., Baars, M., de Koning, B. B., \& Paas, F. (2021). Examining the use of prompts to facilitate self-regulated learning in Massive Open Online Courses. Computers in Human Behavior, 115, 106596. https://doi.org/10.1016/j.chb.2020.106596

Yu, X., Wang, C. X., \& Spector, J. M. (2020). Factors that impact social networking in online selfregulated learning activities. Educational Technology Research and Development, 68(6), 30773095. https://doi.org/10.1007/s11423-020-09843-9

Yuzarion, Y., Agustiana, A. K., Alfaiz, A., Yandri, H., Musdizal, M., \& Aulia, R. (2020). Learning achievement reviewed from self-regulated learning, future orientation, and parental support. COUNS-EDU: The International Journal of Counseling and Education, 5(2). https://doi.org/10.23916/0020200526820

Zhu, Y., Zhang, J. H., Au, W., \& Yates, G. (2020). University students' online learning attitudes and continuous intention to undertake online courses: A self-regulated learning perspective. Educational Technology Research and Development, 68(3), 1485-1519. https://doi.org/10. HYPERLINK "https://doi.org/10.1007/s11423-020-09753-w"1007/s11423-020-09753-w

Zimbardo, P. G., \& Boyd, J. N. (1999). Putting Time in Perspective: A Valid, Reliable IndividualDifferences Metric. Journal of Personality and Social Psychology, 77(6), 1271-1288 